\title{
Protein S100-A8: A potential metastasis-associated protein for breast cancer determined via iTRAQ quantitative proteomic and clinicopathological analysis
}

\author{
JING-MIN ZHONG ${ }^{1,2}$, JING LI $^{3}$, AN-DING KANG ${ }^{4}$, SAN-QIAN HUANG ${ }^{2}$, \\ WEN-BIN LIU ${ }^{2}$, YUN ZHANG ${ }^{2}$, ZHI-HONG LIU ${ }^{2}$ and LIANG ZENG ${ }^{2,5}$
}

\begin{abstract}
${ }^{1}$ Department of Pathology, Union Hospital, Tongji Medical College, Huazhong University of Science and Technology, Wuhan, Hubei 430022; Departments of ${ }^{2}$ Pathology, ${ }^{3}$ Breast Internal Medicine and ${ }^{4}$ Intestinal Surgery, Hunan Cancer Hospital and The Affiliated Cancer Hospital of Xiangya School of Medicine, Central South University, Changsha, Hunan 410013; ${ }^{5}$ Department of Pathology, Guangzhou Women and Children's Medical Center, Guangzhou Medical University, Guangzhou, Guangdong 510623, P.R. China
\end{abstract}

Received November 10, 2015; Accepted January 19, 2017

DOI: $10.3892 / 01.2018 .7958$

\begin{abstract}
Breast cancer is the most common malignancy in females, with metastasis of this type of cancer frequently proving lethal. However, there are still no effective biomarkers to predict breast cancer metastasis. The aim of the present study was, therefore, to analyze breast cancer metastasis-associated proteins and evaluate the association between protein S100-A8 and the prognosis of breast cancer. The isobaric tags for relative and absolute quantitation (iTRAQ) proteomic technique was used to analyze the differential expression of proteins between fresh primary breast tumor (PBT) tissue and fresh paired metastatic lymph nodes (PMLN) tissue. Subsequently, immunohistochemical staining was used to locate and assess the expression of protein S100-A8 in benign breast disease $(n=15)$, primary breast cancer with $(n=109)$ or without $(n=83)$ metastasis, and in paired metastatic lymph nodes $(n=109)$ formalin fixed paraffin embedded (FFPE) tissue. Staining scores were evaluated and the association between protein
\end{abstract}

Correspondence to: Dr Liang Zeng, Department of Pathology, Guangzhou Women and Children's Medical Center, Guangzhou Medical University, 9 Jinsui Road, Tianhe, Guangzhou, Guangdong 510623, P.R. China

E-mail: zlxx03@126.com

Abbreviations: iTRAQ, isobaric tags for relative and absolute quantitation; PBT, primary breast tumor; PMLN, paired metastatic lymph node; iTRAQ, isobaric tags for relative and absolute quantitation; NMBT, non-metastatic breast tumor; BBD, benign breast disease; FFPE, formalin fixed paraffin-embedded; IHC, immunohistochemistry; TIS, total immunostaining score; ER, estrogen receptor; $\mathrm{PR}$, progesterone receptor

Key words: breast neoplasm, neoplasm metastasis, prognosis, isobaric tags for relative and absolute quantitation, protein S100-A8
S100-A8 expression levels and the clinicopathological characteristics of 192 patients with breast cancer were evaluated using the $\chi^{2}$ test. Kaplan-Meier and Cox hazards regression analyses were utilized to investigate the association between the expression of protein S100-A8 and the prognosis of patients with breast cancer. A total of 4,837 proteins were identified using the iTRAQ proteomic technique. Among these proteins, 643 differentially expressed proteins were revealed. Protein S100-A8 expression levels were identified to differ between PBT and PMLN tissues. Immunohistochemical staining suggested a significant difference between NMBT and PMLN $(\mathrm{P}=0.002)$, and also between PBT and PMLN $(\mathrm{P}<0.001)$. Cox hazards regression model analyses suggested that histological grade $(\mathrm{P}=0.031)$ and nodal status $(\mathrm{P}=0.001)$ were risk factors for lymph nodes metastasis of breast cancer. Kaplan-Meier analyses revealed no significant relationship between protein S100-A8 expression level and overall survival rate of patients with breast cancer. In conclusion, by using the iTRAQ proteomic technique and immunohistochemistry staining, it was identified that protein S100-A8 may be associated with lymph nodes metastasis of breast cancer and be a marker for progression of breast cancer.

\section{Introduction}

Breast cancer is the most common malignancy and second leading cause of cancer-associated mortality in females globally $(1,2)$. Breast cancer incidence and mortality rates are high in western countries, while the incidence of breast cancer exhibits an increasing trend in developing countries (1). In China in 2010, there were 208,000 cases of breast cancer, with 55,500 mortalities $(3,4)$. The staging of breast cancer is based on the tumor-node-metastasis system, and distinct stages of disease are associated with various prognosis (5). Tumor size and axillary node status are considered risk factors for breast cancer distant metastases (5), whereas the status of regional lymph nodes is critical in defining the staging, treatment and prognosis of breast cancer (6). Therefore, it is imperative 
to determine the nature of differential protein expression between primary breast tumor (PBT) and paired metastatic lymph node (PMLN) tissues. It is reported that Serpin H1 (7), cluster of differentiation 146 (8) and Ku86 (9) expression may be correlated with breast cancer. However, the molecular mechanisms underlying breast cancer metastasis remain poorly understood.

Various proteins are essential for the normal functions of organisms and the proteome, the entirety of the proteins expressed by a genome of a cell or an organ, alters according to time and environment (10). Therefore, an improved understanding of the processes underlying breast cancer metastasis may be achieved by investigating the differences in protein expression between paired primary breast cancerous tissue and metastasis tissue. A previous study implemented the isobaric tags for relative and absolute quantitation (iTRAQ) proteomic technique to directly analyze the differences in protein expression between these paired tissue types (11). This high-throughput, sensitive and accurate protein detection method identified numerous proteins that may be associated with breast cancer metastasis (11). This previous study demonstrated that protein S100-A8 exhibited a 1.72-fold change between PBT and PMLN, suggesting a potential role for this protein in breast cancer metastasis (11).

Protein S100-A8 is a member of the S100 family of leukocyte proteins, and is a calcium-binding protein (12). The majority of S100 proteins exist as homodimers; however, a number assemble as heterodimers, including S100-A8/S100-A9, encoded by genes clustered on the 1q21 human chromosomal region (13). Protein S100-A8 has previously been identified as a pro-inflammatory factor in arthritis and autoimmune disease (12). As an inflammatory protein, it may serve a role in tumor-stromal interactions (14), and elevated levels of protein S100-A8 have been observed in numerous types of malignancy, including cutaneous squamous cell carcinoma (12), gastric adenocarcinoma (15) and kidney cancer (16). In addition, a previous study demonstrated a correlation between the expression levels of protein S100-A8 and colorectal carcinoma progression, during which this protein may contribute to colorectal carcinoma cell survival and migration via the Wnt/ $\beta$ catenin signaling pathway (17). To the best of our knowledge, the present study is the first to report differences in the expression levels of protein S100-A8 between fresh PBT and fresh PMLN tissues, screened using the iTRAQ proteomic technique. Furthermore, immunohistochemistry (IHC) was utilized to identify variations in protein S100-A8 expression levels in non-metastatic breast tumor (NMBT), PBT, PMLN and benign breast disease (BBD) FFPE tissue. In the present study, further analysis of the correlation between S100-A8 protein expression levels and the clinicopathological factors or overall survival rate of breast cancer was performed.

\section{Materials and methods}

Study subjects and clinical data. A total of 54 paired fresh primary tumor and metastatic lymph node tissues were collected from Hunan Cancer Hospital and The Affiliated Cancer Hospital of Xiangya School of Medicine, Central South University (Changsha, China) between November 2013 and March 2014. All the female patients were initially diagnosed with breast cancer, and did not receive radiotherapy or chemotherapy prior to surgery (modified radical mastectomy). Each axillary lymph node tissue sample was divided into two parts: The first was used for H\&E staining, and the second was stored in liquid nitrogen. A total of 23 paired axillary lymph nodes were identified to be positive.

A total of 207 tissue samples were obtained from the female patients with breast disease who underwent surgery (including radical mastectomy, modified radical mastectomy and local excision) in Hunan Cancer Hospital (Changsha, China) between May 1996 and March 2008 and used for immunohistochemical staining. Among them, 15 patients were diagnosed with BBD, including breast fibrocystic changes, atypic proliferation and fibroadenoma, and 192 patients were diagnosed with breast cancer with $(n=109)$ or without $(n=83)$ regional lymph node metastases. All tissue slides were examined by two pathologists in the Pathology Department of Hunan Cancer Hospital. The pathological parameters of the patients are summarized in Table I. This study was approved by the Research Ethics Committee of Hunan Cancer Hospital and informed consent was obtained from all of the patients.

iTRAQ proteomic analysis. The iTRAQ proteomic analysis was performed using the Fitgene iTRAQ Proteomics Platform (http://www.fitgene.com) according to the manufacturer's protocol. The tissue was placed in liquid nitrogen and ground it until it broke down. A total of $50 \mathrm{mg}$ smashed tissue was added into a $1.5 \mathrm{ml}$ eppendorf tube with $300 \mu \mathrm{l}$ radioimmunoprecipitation assay lysate by pipette and agitated repeatedly. The lysate cells release a viscous material which was sonicated using ultrasound (5\%, $1 \mathrm{sec}$ on, $1 \mathrm{sec}$ off, $10 \mathrm{sec}$ on ultrasound, cooled on ice and repeated 8 times), and then centrifuged $\left(4^{\circ} \mathrm{C}, 14,000 \mathrm{x} \mathrm{g}, 20 \mathrm{~min}\right)$ to obtain the supernatant. The prepared lysates $(200 \mu \mathrm{g})$ were prepared with $4 \mu \mathrm{l}$ reducing reagent (dithiotreitol; United States Biological, Salem, MA, USA) for $1 \mathrm{~h}$ at $60^{\circ} \mathrm{C}$ and then blocked with $2 \mu \mathrm{l}$ cysteine Triethylammonium bicarbonate (TEAB; Sigma-Aldrich; Merck KgaA, Darmstadt, Germany) for $10 \mathrm{~min}$ at room temperature. Following centrifugation $(14,000 \mathrm{x} \mathrm{g,} 20 \mathrm{~min}$, room temperature) and solution collection, $100 \mu 1 \mathrm{MM}$ TEAB was added and discarded and the solution at the bottom of the tube following centrifugation (14,000 x g, $20 \mathrm{~min}$ ) was collected, which was repeated 3 times. Subsequently, trypsin (trypsin to protein mass ratio, 1:100) was added and after $2 \mathrm{~h}$ trypsin was added again (trypsin to protein mass ratio, 1:50). $1 \mathrm{M}$ TEAB was added to make the volume of solution to $50 \mu \mathrm{l}$ and the cell samples were stored overnight at $37^{\circ} \mathrm{C}$. The digested peptide solution was mixed, centrifuged $(14,000 \mathrm{x} \mathrm{g}$, $4^{\circ} \mathrm{C}, 20 \mathrm{~min}$ ), $50 \mu \mathrm{l} 1 \mathrm{M}$ TEAB was added, and sample were centrifuged again $\left(14,000 \mathrm{x} \mathrm{g}, 4^{\circ} \mathrm{C}, 20 \mathrm{~min}\right)$ to obtain $100 \mu \mathrm{l}$ digested sample. A total of $50 \mu \mathrm{l}$ prepared protein sample and iTRAQ reagents were mixed according to the manufacturer's protocol, and the Dionex Ultimate 3000 system (Thermo Fisher Scientific, Inc., Waltham, MA, USA), was used to analyze the labeled protein sample. Protein identification and quantification were achieved by searching the UniProt database (18). Proteomics profiling and database searching based on TripleTOF ${ }^{\circledR} 5600+$ System (SCIEX, Framingham, MA, USA) and 6 ProteinPilot 4.0 (SCIEX) were performed according to the manufacturer's protocol. 
Table I. Clinicopathological characteristics of 192 patients with breast cancer.

\begin{tabular}{|c|c|}
\hline Parameters & Number \\
\hline Median age, years (range) & $45(30-73)$ \\
\hline Median follow up period, months (range) & $80(8-210)$ \\
\hline \multicolumn{2}{|l|}{ Histological type, n (\%) } \\
\hline Ductal & $156(81.3)$ \\
\hline Lobular & $36(18.8)$ \\
\hline \multicolumn{2}{|l|}{ Histological grade, n (\%) } \\
\hline I-II & $35(18.2)$ \\
\hline III & $157(81.8)$ \\
\hline \multicolumn{2}{|l|}{ Nodal status, n (\%) } \\
\hline Negative & $83(43.2)$ \\
\hline Positive & $109(56.8)$ \\
\hline \multicolumn{2}{|l|}{ Tumor size, cm; n (\%) } \\
\hline$\leq 2$ & $58(30.2)$ \\
\hline $2-5$ & $111(57.8)$ \\
\hline$>5$ & $20(10.4)$ \\
\hline Unknown & $3(0.5)$ \\
\hline \multicolumn{2}{|l|}{ Clinical stage, n (\%) } \\
\hline $\mathrm{I}$ & $29(15.1)$ \\
\hline II & $98(51.0)$ \\
\hline III & $62(32.3)$ \\
\hline Unknown & $3(0.5)$ \\
\hline \multicolumn{2}{|l|}{$\mathrm{ER}, \mathrm{n}(\%)$} \\
\hline Negative & $90(46.9)$ \\
\hline Positive & $102(53.1)$ \\
\hline \multicolumn{2}{|l|}{ PR, n (\%) } \\
\hline Negative & $78(40.6)$ \\
\hline Positive & $114(59.4)$ \\
\hline \multicolumn{2}{|l|}{ Cerb B-2, n (\%) } \\
\hline Negative & $58(30.2)$ \\
\hline Positive & $124(64.6)$ \\
\hline Unknown & $10(5.2)$ \\
\hline \multicolumn{2}{|l|}{ Menstrual history, n (\%) } \\
\hline Premenopause & $126(65.6)$ \\
\hline Postmenopause & $66(34.4)$ \\
\hline
\end{tabular}

ER, estrogen receptor; PR, progesterone receptor.

To ensure the reliability and stability of the reported data, the following steps were performed for data quality control. First, prior to database searching, 'Run False Discovery Rate Analysis' was selected in the software ProteinPilot (ProteinPilot $^{\mathrm{TM}}$ Software, version 4.5) for FDR control (SCIEX). Second, according to the SCIEX manufacturer's protocol, the software was set up as Unused $\geq 1.3$ to ensure credibility $\geq 95 \%$. Third, results identified by the reverse database were removed. Fourth, PMLN proteins with abnormal levels of quantified expression were excluded, specifically, when the expression of protein S100-A8 in PMLN was $<0.05$-fold or $>20$-fold compared with that in PBT. Finally, proteins with abnormal quantification between technical repetition and biological repetition were removed. A $>1.5$-fold change of protein expression was considered to indicate a significant difference between fresh PBT and fresh PMLN tissue. Gene ontology (GO) analysis of protein S100-A8 was performed, including biological process (GO ID: 0034641, 0009058, 0007165, 0006950, 0008219, 0002376, 0009056, 0042592, 0007010, 0048870, 0040011, 0051604, 0007155, 0040007), cellular component (GO ID: 0005634, 0005737, 0005829, 0043226, 0005576, 0005886, 0005856, 0005615) and molecular function (GO ID: 0043167, 0008092, 0008289), by searching $\mathrm{GO}$ browsers.

IHC staining. Paraffin-embedded tissue ( $4 \mu \mathrm{m}$ thick, fixed in $10 \%$ neutral formalin for $12-24 \mathrm{~h}$ at room temperature) sections were heated at $60^{\circ} \mathrm{C}$ for $2 \mathrm{~h}$, and then dewaxed by soaking in dimethylbenzene for 10 min twice, followed by rinsing in a graded ethanol series for $5 \mathrm{~min}$ at each concentration. Subsequently, the slides were immersed in citrate retrieval solution (trisodium citrate $3 \mathrm{~g}$, citric acid $0.4 \mathrm{~g}$, pH 6.0, 1,000 ml; Fuzhou Maixin Biotech Co., Ltd., Fuzhou, China), heated using a microwave and cooled to room temperature. A solution of $3 \% \mathrm{H}_{2} \mathrm{O}_{2}$ was added to the tissue samples for $15 \mathrm{~min}$ at room temperature, and the slides were subsequently treated with ultra V block (TL-125-QHD; Thermo Fisher Scientific, Inc.) for $15 \mathrm{~min}$ at room temperature to block nonspecific binding. Subsequently, an anti-protein S100-A8 antibody (1:100; ab92331; Abcam, Cambridge, UK) was added to the tissue sections, and the slides were incubated at $4{ }^{\circ} \mathrm{C}$ overnight. The following day, sections were warmed at room temperature for $1 \mathrm{~h}$ and incubated with primary antibody amplifier (TL-125-QHD) for $15 \mathrm{~min}$ at room temperature. Following this, the tissue samples were incubated with HRP polymer (TL-125-QHD) for $15 \mathrm{~min}$ at room temperature. Next, 3,3'-Diaminobenzidine (DAB; ready-to-use; cat no. TL-125-QHD; Thermo Fisher Scientific, Inc.) was used to stain the tissue sections for a few seconds at room temperature and evaluated by light microscopy (Olympus Corporation, Tokyo, Japan). Finally, the tissue sections were washed with water and stained with hematoxylin. Negative controls were performed by replacing DAB with PBS.

Evaluation of immunostaining. IHC staining was evaluated by two independent pathologists (Pathology Department of Hunan Cancer Hospital and The Affiliated Cancer Hospital of Xiangya School of Medicine, Central South University, Changsha, China). A total immunostaining score was calculated as the proportion score $\mathrm{x}$ the intensity score. The proportion score described the estimated fraction of positive-stained tumor cells as follows: $0,0-4 \% ; 1,5-25 \% ; 2,26-50 \% ; 3,51-75 \%$; $4,>75 \%$. The intensity score represented the estimated staining intensity as follows: 0, no or marginal staining; 1 , weak; 2 , moderate; 3 , intense. The total score ranged from $0-12$, with 0 representing negative, $1-4$ representing weak positive, 6-8 indicating moderate positive and 9-12 describing an intense positive score $(19,20)$.

Statistical analysis. The age and follow-up time of patients is presented as the median (range). Patients were divided into positive and negative groups according to the total 


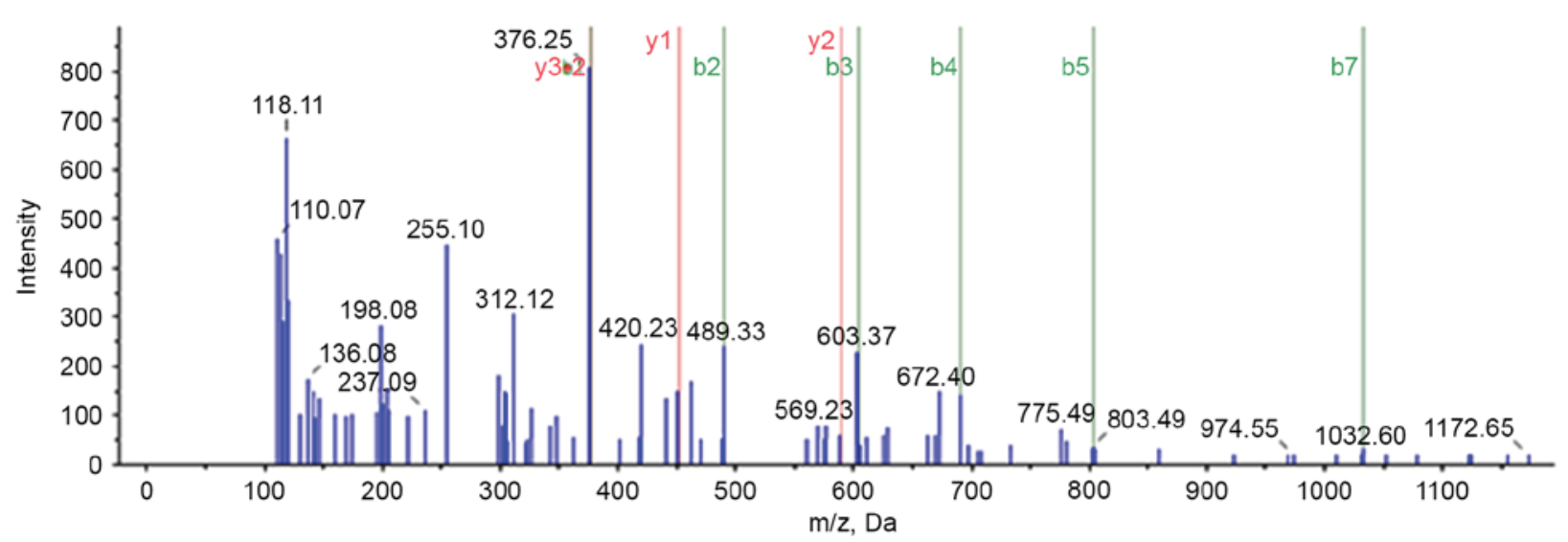

Figure 1. Mass spectrometry of protein S100-A8.

immunostaining score for protein S100-A8. All statistical analyses were performed using SPSS version 20.0 (IBM SPSS, Armonk, NY, USA). McNemar's test was used to examine the difference in $\mathrm{S} 100-\mathrm{A} 8$ protein expression between the positive rate of the PBT and PMLN FFPE tissues. Additionally, the $\chi^{2}$ test was utilized to analyze the difference in the positive rate of protein S100-A8 expression between the BBD, NMBT, PBT and PMLN tissues. Associations between protein S100-A8 positive expression and the clinicopathological characteristics of 192 patients were also examined using the $\chi^{2}$ test. The age and Survival rates of patients with breast cancer with protein S100-A8 positive or negative expression were calculated by using Kaplan-Meier analysis, and were examined using the log-rank test. The Cox proportional hazards model was utilized to determine the association between protein S100-A8 and breast cancer prognosis. $\mathrm{P}<0.05$ was considered to indicate a statistically significant difference.

\section{Results}

iTRAQ proteomic analysis and $G O$ analysis of protein S100-A8. A previous study utilized the iTRAQ proteomic method to analyze differences in protein expression between PBT and PMLN tissues (11). A total of 4,837 proteins were identified, of which 643 were differentially expressed proteins, including 402 upregulated and 241 downregulated, in PMLN tissue, compared with PBT tissue. Protein S100-A8 was observed upregulated 1.72-fold in PMLN tissue, compared to PBT tissue. Further mass spectrometry analysis identified S100-A8 protein (Fig. 1). Based on the GO analysis performed in the current study (Table II), protein $\mathrm{S} 100-\mathrm{A} 8$ is involved in various biological processes, including cellular nitrogen compound metabolism, biosynthetic processes and signal transduction. Furthermore, GO analysis (http://www.uniprot.org/uniprot/P05109) revealed that it is an important constituent of numerous cellular components, including the nucleus, cytoplasm, cytosol, organelles, extracellular regions, plasma membrane and cytoskeleton. The molecular functions of protein S100-A8 include ion binding, cytoskeleton protein binding and lipid binding. This may suggest that protein S100-A8 serves a role in breast cancer metastasis, although further studies are required to elucidate this process.
High expression levels of protein S100-A8 were correlated with metastatic lymph nodes in breast cancer. IHC was utilized to examine the positive expression of protein S100-A8 in the NMBT, PBT and PMLN tissues, as well as the BBD control tissues. It was demonstrated that S100-A8 was located primarily in the cytoplasm of cancerous cells, whilst the nuclei of certain cancerous cells also exhibited sporadic, low-moderate expression of this protein (Fig. 2). In the BBD tissue, epithelial cells exhibited low or negative expression of protein S100-A8, whereas the staining of protein S100-A8 in the PBT tissue was more intense, compared with NMBT and PMLN tissues (Fig. 2). The majority of tissue types exhibited negative expression of protein S100-A8, and moderate or intense expression of protein S100-A8 was observed in BBD and NMBT tissues (Table III). A number of the PBT and PMLN tissues exhibited moderate staining (Table III). The positive expression percentages of protein S100-A8 in NMBT, PBT, PMLN and BBD control tissues were 37.3 (31/83), 34.8 (38/109), 18.4 (20/109) and 13.3\% (2/15), respectively (Fig. 3). Compared with PMLN, the positive expression rate of protein S100-A8 in NMBT $(\mathrm{P}=0.002)$ and PBT $(\mathrm{P}<0.001)$ tissues was significantly higher. However, no significant differences were observed between any other types of tissue used in the study (BBD vs. NMBT, $\mathrm{P}=0.063$; $\mathrm{BBD}$ vs. $\mathrm{PBT}, \mathrm{P}=0.140$; $\mathrm{BBD}$ vs. PMLN, P=1.000; PBT vs MNBT, $\mathrm{P}=0.643$ ) (Fig. 3).

Correlations between protein S100-A8 expression levels and clinicopathological features. The association between protein S100-A8 and the clinicopathological features of 192 patients with breast cancer was further analyzed. The results indicated that the expression of this protein was associated with breast cancer histological type $(\mathrm{P}=0.022)$ and estrogen receptor expression ( $\mathrm{ER} ; \mathrm{P}=0.009$; Table IV). No significant correlation was observed between protein S100-A8 expression and patient age at diagnosis, histological grade, nodal status, tumor size, clinical stage, progesterone receptor (PR) expression, c-erbB2 expression, menstrual history ( $\mathrm{P}>0.05$; Table IV). Additionally, Kaplan-Meier analysis, followed by a log-rank test, was applied to identify the prognostic role of protein S100-A8. Although there was no significant difference observed in the overall survival rate between patients with breast cancer with negative or positive expression of protein S100-A8 ( $\mathrm{P}=0.094)$, a possible association between the positive expression of protein 


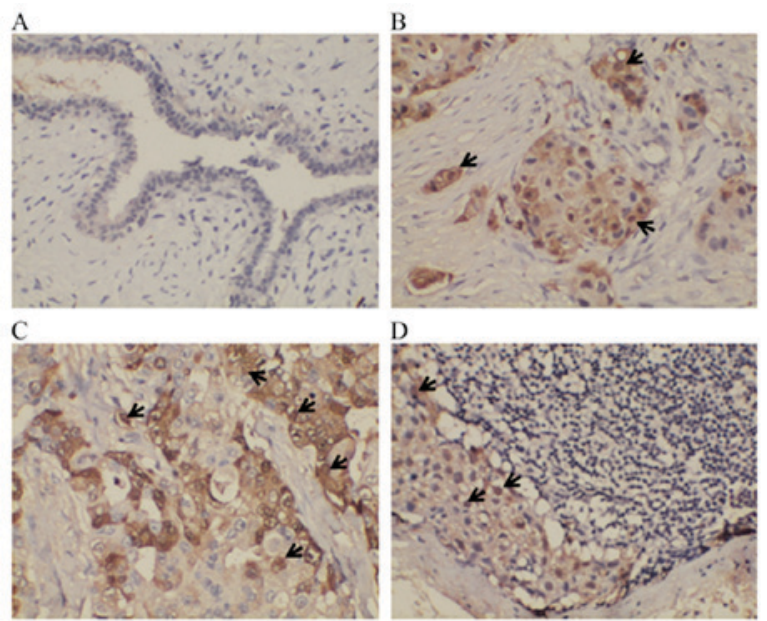

Figure 2. Expression of protein S100-A8 in non-metastatic breast tumor, primary breast tumor, paired metastatic lymph node and control benign breast disease tissues, as detected by immunohistochemical staining. (A) BBD tissue exhibited light or negative expression of protein S100-A8 in epithelial cells. Strong to moderate protein S100-A8 cytoplasm staining was observed in (B) NMBT and (C) PBT. Light protein S100-A8 cytoplasm staining was observed in (D) PMLN. Sporadic and light-moderate expression of protein S100-A8 was identified in the nuclei of cancerous cells (identified by a black arrow). Staining, 3,3'-Diaminobenzidine; magnification, x200. CT, cancerous tissue; LT, lymph tissue.

S100-A8 and an increased survival time following surgery was observed (Fig. 4). According to the Cox proportional hazards model, histological grade $(\mathrm{P}=0.031)$ and nodal status $(\mathrm{P}=0.001)$ were risk factors for poor prognosis of patients with breast cancer (Table V).

\section{Discussion}

Breast cancer is a significant global health burden, causing a substantial number of annual mortalities (2). This disease is hormone dependent, and mortality rates decreased following linking hormone therapy with breast cancer (21). However, this form of cancer is also a systemic disease and $\sim 10-15 \%$ of patients with aggressive disease develop distant metastases within three years of the initial primary tumor diagnosis (5).

Metastasis remains a key risk factor for lowering the overall survival rate in breast cancer, with the regional axillary lymph nodes becoming involved first during this process (22). A previous study demonstrated that, among patients with stage 0 -II breast cancer, local recurrences were 2.8 times less frequent in radically treated patients, compared with conservatively treated patients, for whom lymph node recurrences were twice as common (23). Accurate and effective evaluation of the status of axillary lymph nodes is of prognostic significance in patients with breast cancer (22).

The S100 protein family is exclusive to vertebrates, and is comprised of $10-20 \mathrm{kDa}$ acidic proteins that have previously been associated with inflammation and cancer (24). The genes encoding $\geq 16$ of the $\mathrm{S} 100$ family members, including S100-A8, are clustered on the human chromosomal region 1q21, which frequently undergoes chromosomal rearrangement during tumor development (25). Additionally, protein S100-A8 has been implicated in tumor cell proliferation and metastasis regulation (25-27). Protein S100-A8, also

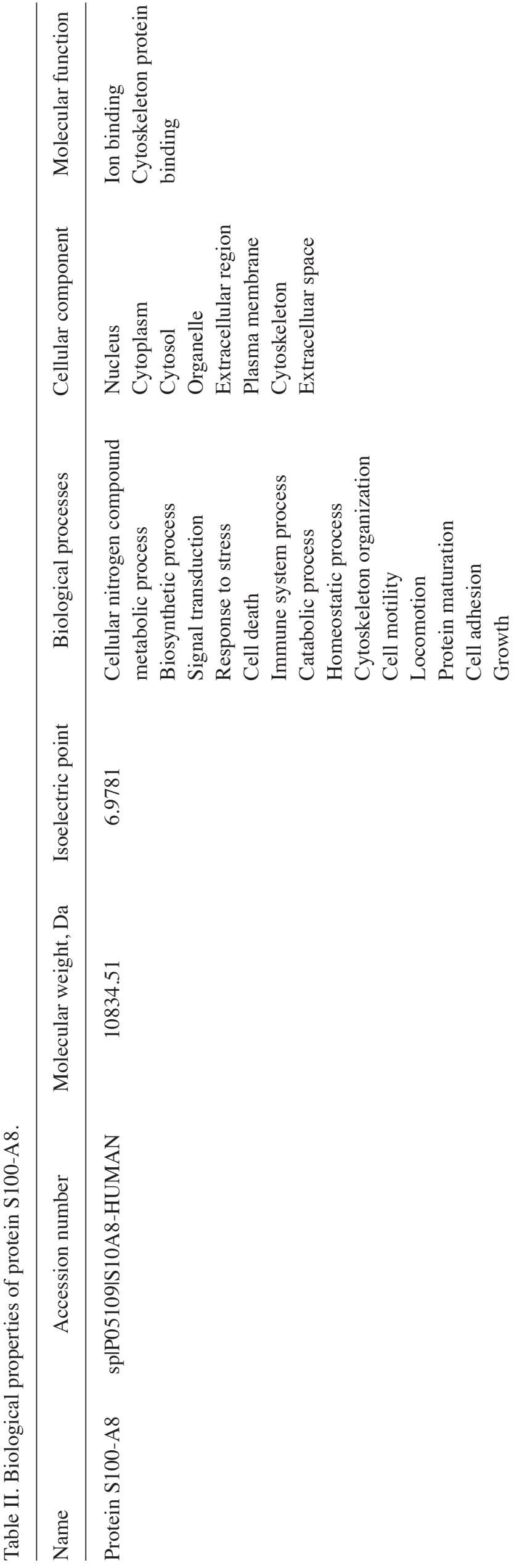


Table III. Expression of protein S100-A8 in NMBT, PBT, PMLN and control BBD tissues.

\begin{tabular}{|c|c|c|c|c|c|c|c|c|}
\hline \multirow[b]{3}{*}{ Variables } & \multicolumn{8}{|c|}{ Protein $\mathrm{S} 100-\mathrm{A} 8$ expression } \\
\hline & \multicolumn{2}{|c|}{ None, TIS (0) } & \multicolumn{2}{|c|}{ Weak, TIS (1-4) } & \multicolumn{2}{|c|}{ Moderate, TIS $(6,8)$} & \multicolumn{2}{|c|}{ Intense, TIS $(9,12)$} \\
\hline & $\mathrm{n}$ & $\%$ & $\mathrm{n}$ & $\%$ & $\mathrm{n}$ & $\%$ & $\mathrm{n}$ & $\%$ \\
\hline BBD & 13 & 86.7 & 2 & 13.3 & 0 & 0 & 0 & 0 \\
\hline NMBT & 52 & 62.7 & 31 & 37.3 & 0 & 0 & 0 & 0 \\
\hline PBT & 71 & 65.1 & 36 & 33.0 & 2 & 1.8 & 0 & 0 \\
\hline PMLN & 89 & 81.7 & 17 & 15.6 & 3 & 2.8 & 0 & 0 \\
\hline
\end{tabular}

BBD, benign breast disease; NMBT, non-metastatic breast tumor; PBT, Primary breast tumor; PMLN, paired metastatic lymph node; TIS, total immunostaining score.

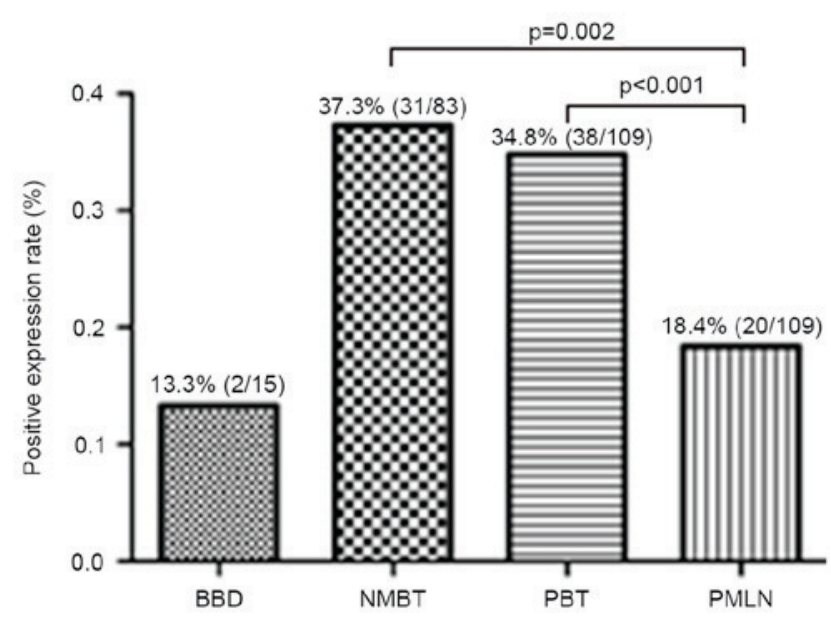

Figure 3. Positive expression of protein S100-A8 in NMBT, primary breast tumor, PMLN and BBD control tissues. The results revealed significant differences between NMBT and PMLN and between PBT and PMLN, which were statistically evaluated by the $\chi^{2}$ test. NMBT, non-metastatic breast tumor; PBT, primary breast tumor; PMLN, paired metastatic lymph node; $\mathrm{BBD}$, benign breast disease.

known as myeloid-related protein 8 , is a small intracellular calcium-binding protein that has also been reported to be expressed and secreted in the extracellular matrix of prostate cancer cells (28). Katanov et al (29) emphasized the important role of inflammation in breast cancer stroma, and suggested that nuclear factor (NF)- $\mathrm{kB}$ may be a potential inhibitory target in tumor-adjacent stromal cells. Additionally, protein S100-A8 has been identified to be a novel member of the NF- $\mathrm{KB}$ signaling pathway (30), participating in the development and progression of laryngeal squamous cell carcinoma via its interaction with human leukocyte antigen B (31). A previous study also demonstrated that zinc may promote and impede tumorigenesis by activating and suppressing the interaction between protein S100-A8 and the receptor for advanced glycation endproducts, as well as downstream NF-signaling (32).

In a previous study, the protein expression profiles in primary tumor and paired metastatic lymph node tissues were compared using the iTRAQ proteomic method, during which protein S100-A8 was identified to be upregulated

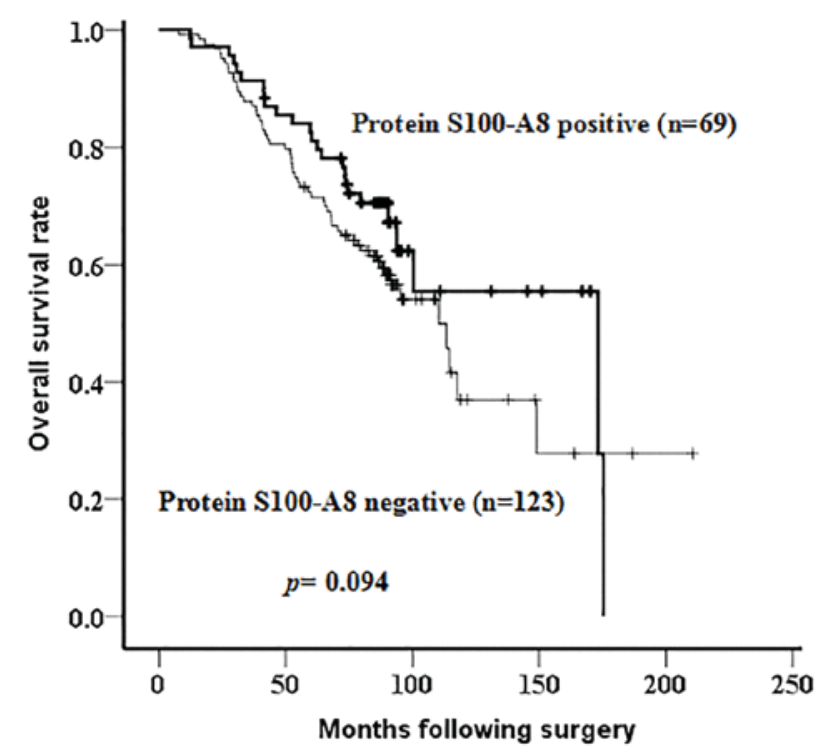

Figure 4. Kaplan-Meier survival curves for patients with positive and negative protein S100-A8 expression. No significant difference was observed between the two groups (log-rank; $\mathrm{P}=0.094)$. The thick curve represents the positive expression of protein S100-A8 while the thin curve represents negative expression.

(1.72-fold) in PMLN, compared with PBT (11). This suggested a potential association between protein S100-A8 and breast cancer metastasis (11). Therefore, IHC staining was applied to analyze the differences in $\mathrm{S} 100-\mathrm{A} 8$ protein expression in NMBT, PBT, PMLN and BBD control tissues. However, IHC staining exhibited decreased protein S100-A8 expression levels in PMLN, compared with PBT. The contrast between these two results is potentially due to the limited number of fresh tissue samples used in the current study. Furthermore, PMLN with the largest breast cancer metastases, or where lymph tissue was completely replaced by metastatic tissue, were preferentially selected. Although there is a discrepancy between the ITRAQ proteomic analysis and the IHC staining results, the IHC sample size was larger, and the expression levels of protein S100-A8 exhibited a significant difference between PBT and PMLN tissues in ITRAQ analysis and IHC staining. These results may suggest that protein S100-A8 is a potential candidate metastatic marker in breast cancer. 
Table IV. Association between protein S100-A8 expression levels and the clinicopathological characteristics of 192 patients with breast cancer.

S100-A8 protein expression

Characteristic

$\mathrm{N}$

No Yes

P-value

Age at diagnosis, years

$<50$

114

76

38

0.363

$\geq 50$

78

47

31

Histological type

Ductal

156

94

62

Lobular

36

29

7

Histological grade

I-II

III

Nodal status

Negative

Positive

83

109

Tumor size, $\mathrm{cm}$

$\leq 2$

2-5

58

111

20

$>5$

Unknown

Clinical stage

I

II

III

Unknown

ER

Negative

Positive

PR

Negative

Positive

Cerb B-2

Negative

Positive

Unknown

Menstrual history

Premenopause

Postmenopause

3

29

98

62

3

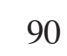

102

78

114

\section{8}

124

10

126

66

32

$71 \quad 38$

40

69

12
20

66

35

49

74

48

75

42

75

84

39

31

31

38

18

42

8

0.630

8

9

32

27

41

28

30

39

16

39

42

27

${ }^{\mathrm{a}} \mathrm{P}<0.05$, according to $\chi^{2}$ test. Unknown cases are excluded from $\mathrm{p}$-value calculations. ER, estrogen receptor expression; PR, progesterone receptor expression.

Table V. Cox regression analysis of risk factors for short overall survival time of breast cancer patients.

\begin{tabular}{lcccrr}
\hline Variables & B & SE & Wald & Sig. & Exp(B) $(95 \%$ CI $)$ \\
\hline Nodal status & 0.917 & 0.273 & 11.243 & $0.001^{\mathrm{a}}$ & $2.501(1.464-4.275)$ \\
Histological grade & 0.924 & 0.428 & 4.649 & $0.031^{\mathrm{a}}$ & $2.518(1.088-5.830)$ \\
\hline
\end{tabular}

${ }^{\mathrm{a}} \mathrm{P}<0.05 .95 \% \mathrm{CI}, 95 \%$ confidence interval. 
In the present study, the correlation between protein S100-A8 expression and the clinicopathological features of 207 patients with breast cancer was analyzed. The results demonstrated that protein S100-A8 expression levels were significantly associated with the histological type $(\mathrm{P}=0.022)$ and ER positive expression $(\mathrm{P}=0.009)$ of breast cancer tumors. Concordantly, Parris et al (33) proposed a combined predictive model for breast cancer outcomes, containing a four-marker panel ( $\alpha$-2-glycoprotein 1, zinc-binding, prolactin-inducible protein, S100-A8 and ubiquitin conjugating enzyme E2 C), which suggested a significant correlation with histological grade, tumor inflammatory cell infiltration, ER and PR status.

In addition, the present study applied Kaplan-Meier analysis to analyze the impact of altered S100-A8 expression levels on the prognosis of patients with breast cancer. Although no significant association was observed between the overall survival rate of patients with breast cancer and the expression of this protein $(\mathrm{P}=0.094)$, positive $\mathrm{S} 100-\mathrm{A} 8$ expression was revealed to potentially contribute to a longer overall survival time for patients with breast cancer. This protein has also been reported to be a survival-associated factor in oropharyngeal squamous cell carcinoma (34). However, protein S100-A8 was also demonstrated to be a marker of poor prognosis for invasive ductal carcinoma of the breast (35). The aforementioned four-marker panel proposed by Parris et al (33) may be used to predict an unfavorable clinical outcome of patients with breast cancer. The present study implemented the Cox proportional hazards model, which demonstrated that protein S100-A8 is not an independent risk factor for prognosis in breast cancer.

S100-A8 also assembles heterodimers with S100-A9, which increases matrix metalloproteinase (MMP)-2 or MMP-12 expression and activity to promote tumor cell migration and invasion $(36,37)$. This suggests that the interaction of S100-A8 within heterodimers is able to affect its activity during the process of breast cancer progression. Therefore, further studies examining the role of S100-A8 in breast cancer metastasis, and using a larger number of tissue specimens, are required.

In conclusion, a number of proteins associated with breast cancer metastasis were identified using iTRAQ. Protein S100-A8 presented a positive association with breast cancer metastasis, which may provide a potential biomarker for predicting breast cancer lymph node metastasis. As the exact association of this protein with the prognosis of patients with breast cancer, and the mechanism underlying the process by which it may promote tumor cell migration and invasion is unclear, further studies are required to investigate the function of S100-A8 in this complex metastatic network. This may provide a novel and effective prognostic biomarker, aiding the treatment of breast cancer.

\section{Acknowledgements}

This study was supported by the Hunan Province Science and Technology Project (grant no. 2014FJ6090). The authors would like to thank the proteomic technique platform Fitgene Biotechnology Co., Ltd., (Guangzhou, China) for providing technical support and professional advice regarding iTRAQ proteomic technology.

\section{References}

1. Torre LA, Bray F, Siegel RL, Ferlay J, Lortet-Tieulent J and Jemal A: Global cancer statistics, 2012. CA Cancer J Clin 65: 87-108, 2015.

2. Libson S and Lippman M: A review of clinical aspects of breast cancer. Int Rev Psychiatry 26: 4-15, 2014.

3. Zeng H, Zheng R, Zhang S, Zou X and Chen W: Female breast cancer statistics of 2010 in China: Estimates based on data from 145 population-based cancer registries. J Thorac Dis 6: 466-470, 2014.

4. Ferlay J, Soerjomataram I, Dikshit R, Eser S, Mathers C, Rebelo M, Parkin DM, Forman D and Bray F: Cancer incidence and mortality worldwide: Sources, methods and major patterns in GLOBOCAN 2012. Int J Cancer 136: E359-E386, 2015.

5. Weigelt B, Peterse JL and van't Veer LJ: Breast cancer metastasis: Markers and models. Nat Rev Cancer 5: 591-602, 2005.

6. Pinheiro DJ, Elias S and Nazário AC: Axillary lymph nodes in breast cancer patients: Sonographic evaluation. Radiol Bras 47: 240-244, 2014.

7. Hill JJ, Tremblay TL, Pen A, Li J, Robotham AC, Lenferink AE, Wang E, O'Connor-McCourt M and Kelly JF: Identification of vascular breast tumor markers by laser capture microdissection and label-free LC-MS. J Proteome Res 10: 2479-2493, 2011.

8. Zeng Q, Zhang P, Wu Z, Xue P, Lu D, Ye Z, Zhang X, Huang Z, Feng J, Song L, et al: Quantitative proteomics reveals ER-a involvement in CD146-induced epithelial-mesenchymal transition in breast cancer cells. J Proteomics 103: 153-169, 2014.

9. Lagadec C, Romon R, Tastet C, Meignan S, Com E, Page A, Bidaux G, Hondermarck $\mathrm{H}$ and Le Bourhis X: Ku86 is important for TrkA overexpression-induced breast cancer cell invasion. Proteomics Clin Appl 4: 580-590, 2010.

10. Chen ZC: Advances in cancer proteomics study. Ai Zheng 23: 113-117, 2004 (In Chinese).

11. Zeng L, Zhong J, He G, Li F, Li J, Zhou W, Liu W, Zhang Y, Huang S, Liu Z and Deng X: Identification of nucleobindin-2 as a potential biomarker for breast cancer metastasis using iTRAQ-based quantitative proteomic analysis. J Cancer 8: 3062-3069, 2017.

12. Choi DK, Li ZJ, Chang IK, Yeo MK, Kim JM, Sohn KC, Im M, Seo YJ, Lee JH, Kim CD and Lee Y: Clinicopathological roles of S100A8 and S100A9 in cutaneous squamous cell carcinoma in vivo and in vitro. Arch Dermatol Res 306: 489-496, 2014.

13. Foell D and Roth J: Proinflammatory S100 proteins in arthritis and autoimmune disease. Arthritis Rheum 50: 3762-3771, 2004.

14. Basso D, Bozzato D, Padoan A, Moz S, Zambon CF, Fogar P, Greco E, Scorzeto M, Simonato F, Navaglia F, et al: Inflammation and pancreatic cancer: Molecular and functional interactions between S100A8, S100A9, NT-S100A8 and TGF 31 . Cell Commun Signal 12: 20, 2014.

15. Choi JH, Shin NR, Moon HJ, Kwon CH, Kim GH, Song GA, Jeon TY, Kim DH, Kim DH and Park DY: Identification of S100A8 and S100A9 as negative regulators for lymph node metastasis of gastric adenocarcinoma. Histol Histopathol 27:1439-1448, 2012.

16. Mirza Z, Schulten HJ, Farsi HM, Al-Maghrabi JA, Gari MA, Chaudhary AG, Abuzenadah AM, Al-Qahtani MH and Karim S: Impact of S100A8 expression on kidney cancer progression and molecular docking studies for kidney cancer therapeutics. Anticancer Res 34: 1873-1884, 2014.

17. Duan L, Wu R, Ye L, Wang H, Yang X, Zhang Y, Chen X, Zuo G, Zhang Y, Weng Y, et al: S100A8 and S100A9 are associated with colorectal carcinoma progression and contribute to colorectal carcinoma cell survival and migration via Wnt/b-catenin pathway. PLoS One 26: e62092, 2013.

18. The UniProt Consortium: UniProt: The universal protein knowledgebase. Nucleic Acids Res 45: D158-D169, 2017.

19. Chang X, Xu X, Ma J, Xue X, Li Z, Deng P, Zhang S, Zhi Y, Chen J and Dai D: NDRG1 expression is related to the progression and prognosis of gastric cancer patients through modulating proliferation, invasion and cell cycle of gastric cancer cells. Mol Biol Rep 41: 6215-6223, 2014.

20. Gastl G, Spizzo G, Obrist P, Dünser M and Mikuz G: Ep-CAM overexpression in breast cancer as a predictor of survival. Lancet 356: 1981-1982, 2000.

21. Chlebowski RT, Kuller LH, Prentice RL, Stefanick ML, Manson JE, Gass M, Aragaki AK, Ockene JK, Lane DS, Sarto GE, et al: Breast cancer after use of estrogen plus progestin in postmenopausal women. N Engl J Med 360: 573-587, 2009. 
22. Liu D, Chen Y, Deng M, Xie G, Wang J, Zhang L, Liu Q, Yuan P and Feng X: Lymph node ratio and breast cancer prognosis: A meta-analysis. Breast Cancer 21: 1-9, 2014.

23. Ursaru M, Jari I, Popescu R, Negru D, Naum A and Scripcariu V: Multifactorial analysis of local and lymph node recurrences after conservative or radical surgery for stage 0 -II breast cancer. Rev Med Chir Soc Med Nat Lasi 118: 1062-1067, 2014.

24. Foell D, Wittkowski H, Vogl T and Roth J: S100 proteins expressed in phagocytes: A novel group of damage-associated molecular pattern molecules. J Leukoc Biol 81: 28-37, 2007.

25. Kim SK, Kim EJ, Leem SH, Ha YS, Kim YJ and Kim WJ: Identification of S100A8-correlated genes for prediction of disease progression in non-muscle invasive bladder cancer. BMC Cancer 10: 21, 2010

26. Cross SS, Hamdy FC, Deloulme JC and Rehman I: Expression of S100 proteins in normal human tissues and common cancers using tissue microarrays: S100A6, S100A8, S100A9 and S100A11 are all overexpressed in common cancers. Histopathology 46 : 256-269, 2005

27. Salama I, Malone PS, Mihaimeed F, Jones JL: A review of the S100 proteins in cancer. Eur J Surg Oncol 34: 357-364, 2008

28. Hermani A, Hess J, De Servi B, Medunjanin S, Grobholz R, Trojan L, Angel P and Mayer D: Calcium-binding proteins S100A8 and S100A9 as novel diagnostic markers in human prostate cancer. Clin Cancer Res 11: 5146-5152, 2005.

29. Katanov C, Lerrer S, Liubomirski Y, Leider-Trejo L, Meshel T, Bar J, Feniger-Barish R, Kamer I, Soria-Artzi G, Kahani H, et al: Regulation of the inflammatory profile of stromal cells in human breast cancer: Prominent roles for TNF- $\alpha$ and the NF- $\kappa \mathrm{B}$ pathway. Stem Cell Res Ther 6: 87, 2015.
30. Gebhardt C, Németh J, Angel P and Hess J: S100A8 and S100A9 in inflammation and cancer. Biochem Pharmacol 72: 1622-1631, 2006.

31. Fu WN, Guo Y, Huang DF, Shang C and Sun KL: Novel partners of S100A8 identified in laryngeal cancer cell lines. Zhonghua Yi Xue Yi Chuan Xue Za Zhi 24: 266-270, 2007.

32. Taccioli C, Wan SG, Liu CG, Alder H, Volinia S, Farber JL, Croce CM and Fong LY: Zinc replenishment reverses overexpression of the proinflammatory mediator S100A8 and esophageal preneoplasia in the rat. Gastroenterology 136: 953-966, 2009.

33. Parris TZ, Kovács A, Aziz L, Hajizadeh S, Nemes S, Semaan M, Forssell-Aronsson E, Karlsson P and Helou K: Additive effect of the AZGP1, PIP, S100A8 and UBE2C molecular biomarkers improves outcome prediction in breast carcinoma. Int $\mathrm{J}$ Cancer 134: 1617-1629, 2014.

34. Funk S, Mark R, Bayo P, Flechtenmacher C, Grabe N, Angel P, Plinkert PK and Hess J: High S100A8 and S100A12 protein expression is a favorable prognostic factor for survival of oropharyngeal squamous cell carcinoma. Int J Cancer 136: 2037-2046, 2015.

35. Arai K, Takano S, Teratani T, Ito Y, Yamada T and Nozawa R: S100A8 and S100A9 overexpression is associated with poor pathological parameters in invasive ductal carcinoma of the breast. Curr Cancer Drug Targets 8: 243-252, 2008.

36. Kwon CH, Moon HJ, Park HJ, Choi JH and Park DY: S100A8 and S100A9 promotes invasion and migration through $\mathrm{p} 38$ mitogen-activated protein kinase-dependent NF- $\mathrm{BB}$ activation in gastric cancer cells. Mol Cells 35: 226-234, 2013.

37. Silva EJ, Argyris PP, Zou X, Ross KF and Herzberg MC: S100A8/A9 regulates MMP-2 expression and invasion and migration by carcinoma cells. Int J Biochem Cell Biol 55: 279-287, 2014. 